\title{
AN EMPIRICAL V-NOTCH WEIR EQUATION AND STANDARD PROCEDURE TO ACCURATELY ESTIMATE DRAINAGE DISCHARGE
}

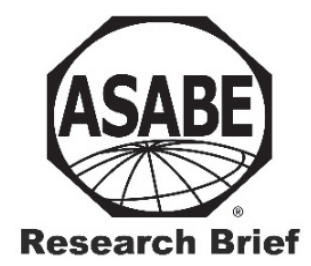

\author{
Md Sami Bin Shokrana', Ehsan Ghane ${ }^{1, *}$ \\ ${ }^{1}$ Biosystems and Agricultural Engineering, Michigan State University, East Lansing, Michigan, USA. \\ * Correspondence: ghane@msu.edu.
}

\section{Highlights}

- An empirical flow equation was developed for a metal-edge sharp-crest V-notch weir.

- A top-down approach was used to determine the height of the V-notch apex.

- A combination of the weighing method and a flow meter was used to develop the stage-discharge equation.

- A standard procedure was presented to accurately estimate the flow rate.

\begin{abstract}
A reliable empirical flow equation for $V$-notch weirs will provide flow estimates that can be used to calculate nutrient loads leaving fields with subsurface drainage. The objective of this study was to develop such an equation for an AgriDrain metal-edge sharp-crest $45^{\circ} \mathrm{V}$-notch weir. In this undertaking, we measured flow rate with a combination of the weighing method for low flow and a turbine flow meter for high flow. The head of water (H) was measured inside a 25-cm AgriDrain control structure with a three-step method. First, we measured the water level (a) and height of the control structure (b). Second, we measured the height of the $V$-notch apex (c). Third, we calculated head using this equation: H= $(b-a)-(b-c)$. Based on the flow meter readings $(Q)$ and $H$ measurements, we developed the following stage-discharge equation: $Q=0.749 H^{2.25}$, with $Q$ in liters per minute and $H$ in centimeters. This equation is valid for an $H$ less than the height of the $V$-notch (i.e., flow through the V-notch) with unsubmerged flow. Based on field experience, we provide a standard procedure for accurate estimation of drainage discharge. In conclusion, the stage-discharge equation developed in this study can provide reliable flow estimates for subsurface drainage studies.
\end{abstract}

Keywords. Flow rate, Metal-edge weir, Sharp-crest weir, Subsurface drainage, Tile drainage, Weir placement.

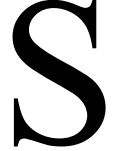
ubsurface drainage is a widely used practice that removes excess water from poorly drained soils (Konyha et al., 1992; Schilling and Helmers, 2008; King et al., 2014; Mourtzinis et al., 2021) and is implemented by installing perforated plastic drainage pipes below the soil surface. In addition to removing water, these pipes allow nitrogen and phosphorus to drain out of the soil. These can accumulate in lakes and oceans and cause eutrophication (Fausey et al., 1995; King et al., 2015; Ghane et al., 2016; Pease et al., 2018).

Several drainage best management practices (BMPs: controlled drainage, saturated buffer, denitrifying bioreactor, etc.) have the potential to mitigate this issue of nutrient transport. Some of these BMPs require installation of an inline water-level control structure, which manages drainage discharge at the edge of the field (Christianson et al., 2012;

cc)(3) $\Theta$ The authors have paid for open access for this article. This c. $\mathrm{BY}$ NC ND work is licensed under a Creative Commons AttributionNonCommercial-NoDerivatives 4.0 International License https://creative commons.org/licenses/by-nc-nd/4.0/

Submitted for review on 2 April 2021 as manuscript number NRES 14617; approved for publication as a Research Brief by the Natural Resources \& Environmental Systems Community of ASABE on 6 October 2021.
Ghane et al., 2012; Jaynes and Isenhart, 2014; Williams et al., 2015). To assess the effectiveness of the BMPs in reducing nutrient loads, it is necessary to estimate drainage discharge, and an accurate method for doing so is needed.

Researchers have used various devices and methods, including weirs, sump pumps, tipping buckets, and ultrasonic flow measurements to estimate flow rate ( Kanwar et al., 1999; Chun and Cooke, 2008). Calculating flow rate with a weir is one of the most inexpensive and reliable methods available to assess subsurface drainage systems. Weirs are placed inside a control structure to measure drainage discharge from the field. Researchers use different types of weirs (e.g., rectangular, triangular or V-notch, or trapezoidal) to develop flow equations (Walkowiak, 2006). These equations are mostly empirical and vary based on the design and dimension of the weir.

In 2018, AgriDrain (Adair, Iowa) introduced a new type of metal-edge sharp-crest $\mathrm{V}$-notch weir. The reason for the new design was to manufacture a standard sharp-crest Vnotch weir as opposed to a broad-crest V-notch weir (Huffman et al., 2013). The advantage of a sharp-crest Vnotch weir is to prevent the jet of water leaving the weir apex from adhering to any part of the weir's downstream side (Walkowiak, 2006). Instead, the jet of water would spring 
free of the apex, with minimal contact with the downstream side of the weir. As a result, the new design improves the accuracy of flow measurements. Christianson et al. (2019) calibrated these sharp-crest V-notch weirs for 15- and 25-cm AgriDrain control structures. These dimensions "15- and $25-\mathrm{cm}$ " refer to the diameter of the drainage pipe connected to the control structure. The equation developed from their experiment for flow rate as related to the depth of water from the apex of the V-notch, often called the head of water, is:

$$
\mathrm{Q}=0.66 \mathrm{H}^{2.28}
$$

where

$\mathrm{Q}=$ flow $\operatorname{rate}(\mathrm{L} / \mathrm{min})$, and

$\mathrm{H}=$ head of water $(\mathrm{cm})$

Christianson et al. (2019) also calibrated the flow rate measured with these different-sized $(15-$ and $25-\mathrm{cm}) \mathrm{V}$ notch weirs at three different placements inside the control structure: on the bottom of the structure, $48 \mathrm{~cm}$ above it, and $97 \mathrm{~cm}$ above it. They found no significant differences in the equations they developed to calculate flow rate, regardless of placement or the size of the weir. The authors developed their flow equation with a weighing method of flow measurement. Due to the importance of V-notch weir flow equations in subsurface drainage studies, there is a need to verify this equation in another setting. Also, Christianson et al. (2019) developed their equation for a head of about $14 \mathrm{~cm}$, which does not cover the entire height of a standard metaledge sharp-crest $45^{\circ} \mathrm{V}$-notch weir.

The objective of this study was to develop a stage-discharge relationship for an AgriDrain metal-edge sharp-crest $45^{\circ} \mathrm{V}$-notch weir. In our calibration method, we used a combination of the weighing method and a flow meter to measure flow rates. The stage-discharge equation that we developed should accurately estimate drainage discharge when water is flowing through the $\mathrm{V}$-notch weir. This equation will aid in evaluating the effectiveness of BMPs in reducing nutrient load.

\section{MATERIALS AND METHODS COMMONLY USED V-NOTCH EQUATIONS}

The triangular or V-notch weirs are popular in drainage studies because of their high accuracy at low flow rates (Troskolanski, 1960; USGS, 1982; Haan et al., 1994; Chanson and Wang, 2013). The estimation of flow through $\mathrm{V}$-notch weir follows a stage-discharge relationship. The discharge is directly proportional to the head. The discharge equation for a sharp-crest $\mathrm{V}$-notch weir with an apex angle $\Theta$ is written as (World Meteorological Organization, 1971):

$$
\mathrm{Q}=(8 / 15) C_{d}(2 \mathrm{~g})^{0.5} \tan (\Theta / 2) \mathrm{H}^{2.5}
$$

where

$\mathrm{Q}=$ flow rate $(\mathrm{L} / \mathrm{min})$,

$\mathrm{H}=$ head of water $(\mathrm{cm})$,

$\mathrm{g}=$ acceleration due to gravity, and

$\mathrm{C}_{\mathrm{d}}=$ discharge coefficient. For a triangular sharp-crest weir with an angle of $90^{\circ}, \mathrm{C}_{\mathrm{d}}$ is assumed to be 0.61

(Bijankhan and Ferro, 2017).
A simplified equation was developed (USGS, 1982) to calculate flow rate through thin-plate $\mathrm{V}$-notch weirs when the angle of $\mathrm{V}$-notch was less than or equal to $90^{\circ}$. For a metal-edge sharp-crest $45^{\circ} \mathrm{V}$-notch weir, the United States Geological Survey (USGS) equation is:

$$
\mathrm{Q}=0.343 \mathrm{H}^{2.5}
$$

where

$\mathrm{Q}=$ flow rate $(\mathrm{L} / \mathrm{min})$, and

$\mathrm{H}=$ head of water $(\mathrm{cm})$.

Since the area of the V-notch weir is quite small compared to the cross-sectional area of the channel, it is safe to neglect the approach velocity for $\mathrm{V}$-notch angles of $90^{\circ}$ or less (USGS, 1982). While this may be true for open channel flow, but may not apply to the subsurface drainage control structures. Depending on the diameter of the pipe and the slope leading into the control structure, the approach velocity can be enough to create turbulence inside the structure. Another study suggested that if two criteria are satisfied, it is acceptable to ignore the approach velocity in a V-notch weir (World Meteorological Organization, 1971). Those criteria are met if $\mathrm{H} / \mathrm{P}<0.4$ (where $\mathrm{H}$ is the head of water, $\mathrm{P}$ is the distance from the bottom of the structure to the apex of the $\mathrm{V}$-notch weir) and $\mathrm{H} / \mathrm{B}<0.2$ (where $\mathrm{B}$ is the width of the $\mathrm{V}$-notch board). These criteria may be invalid in subsurface drainage control structures, so we cannot use the USGS equation. Therefore, there is a need to calibrate the V-notch weir inside a control structure.

In our experiment, we fitted flow and head data to a simplified version of equation 2 . This equation is:

$$
\mathrm{Q}=\mathrm{aH}^{\mathrm{b}}
$$

where $\mathrm{a}$ and $\mathrm{b}$ are fitted parameters from a regression analysis.

\section{EXPERIMENTAl Setup and Flow Measurement}

Our experiment to develop a flow equation was conducted in September 2021 near a pond located at south campus of Michigan State University. The setup is shown in figure 1 (Supplementary information: fig. S1, https://figshare.com/s/074abddcaa5da99095ff). We used a Flomec GPI turbine flow meter (model number: TM20NQ9GMB, Wichita, Kansas) with a flow measurement range of $75-757 \mathrm{~L} / \mathrm{min}(20-200 \mathrm{gal} / \mathrm{min}$, with a $\pm 3 \%$ accuracy). This flow meter was factory calibrated by the manufacturer.

It is important to note that the experimental flow range (16-409 L/min) from this study was determined based on experience and literature review. For a $25-\mathrm{cm}$ control structure, $17 \mathrm{~cm}$ is the maximum head that can be obtained when water is flowing through an Agri Drain metal-edge sharp-crest $45^{\circ}$ V-notch weir. Therefore, this experimental flow range mentioned above approximately covers the entire flow range through a $\mathrm{V}$-notch weir.

For the lower flow rates $(16-59 \mathrm{~L} / \mathrm{min})$, we used a weighing method. In this method, we held a 5-gal bucket at the outlet of the control structure, recorded the time required to collect a specific volume of water in the bucket, weighed the bucket on a portable scale (Brecknell PS-USB, Fairmont, Minn.), then calculated the flow rate. We took three weight readings (triplicate readings) for each flow rate and used 
their mean value as our final flow reading. It is important to note that the weighing scale was calibrated with known weights before and after the experiment. For the higher flow rates (105-409 L/min), we used the Flomec GPI turbine flow meter mentioned above.

The upstream chamber of the control structure was connected to a $25-\mathrm{cm}$ (10 in.) SDR-35 pipe. We reduced the pipe size to $5 \mathrm{~cm}$ (2 in.) to accommodate the flow meter. We pumped (Pacer pumps, model number: SEB2ULE51C, Lancaster, Pa.) water out of a pond with a flexible polyvinyl chloride (PVC) pipe. The benefit of using a pond as the water source is that the water level in the pond does not drop as compared to a water tank, which reduces the fluctuation of the pumped water. Nevertheless, we still saw minor fluctuation in the pumped water, as is expected with the pump. To reduce the effect of flow fluctuation, we took numerous (at least 4) flow meter readings for each measurement and took an average of those readings as our final flow.

The discharge side of the pump was connected to a 100ft long blue lay flat discharge hose, which supplied water to the flow meter. The V-notch weir (fig. 2) was placed on top of a 17.8-cm tall (7-in.; height does not include the thickness of compressed rubber gasket) bottom board inside the control structure.

It is important to note that there was a minor difference $(17.0$ vs. $16.5 \mathrm{~cm})$ in the height of the $\mathrm{V}$-notch in our experiment compared to the one used by Christianson et al. (2019), even though both are standard V-notch weirs from the same manufacturer. The total height and angle of the Vnotch board were the same for both studies. Therefore, any calibrated stage-discharge equation is still valid when the angle of the sharp-crest V-notch weir is the same.

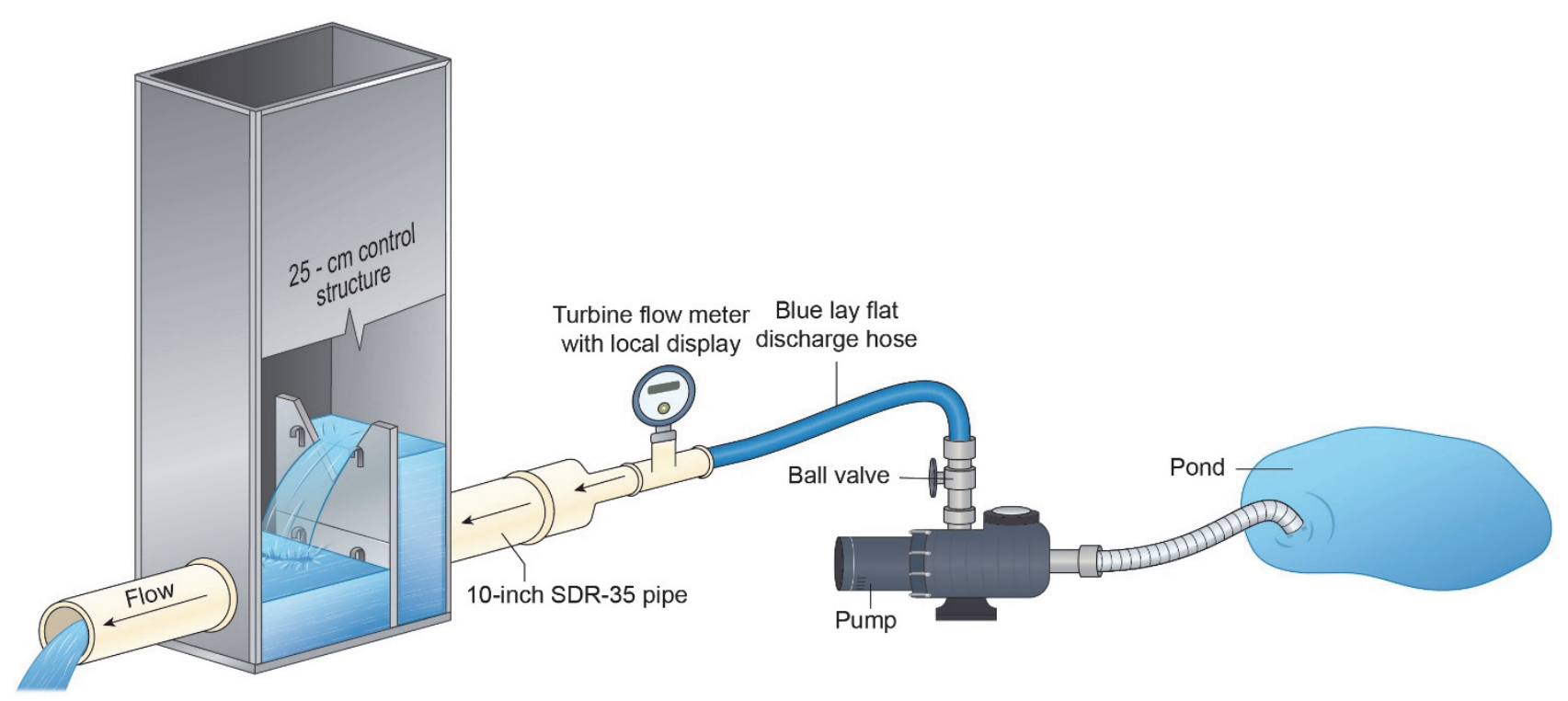

(a)

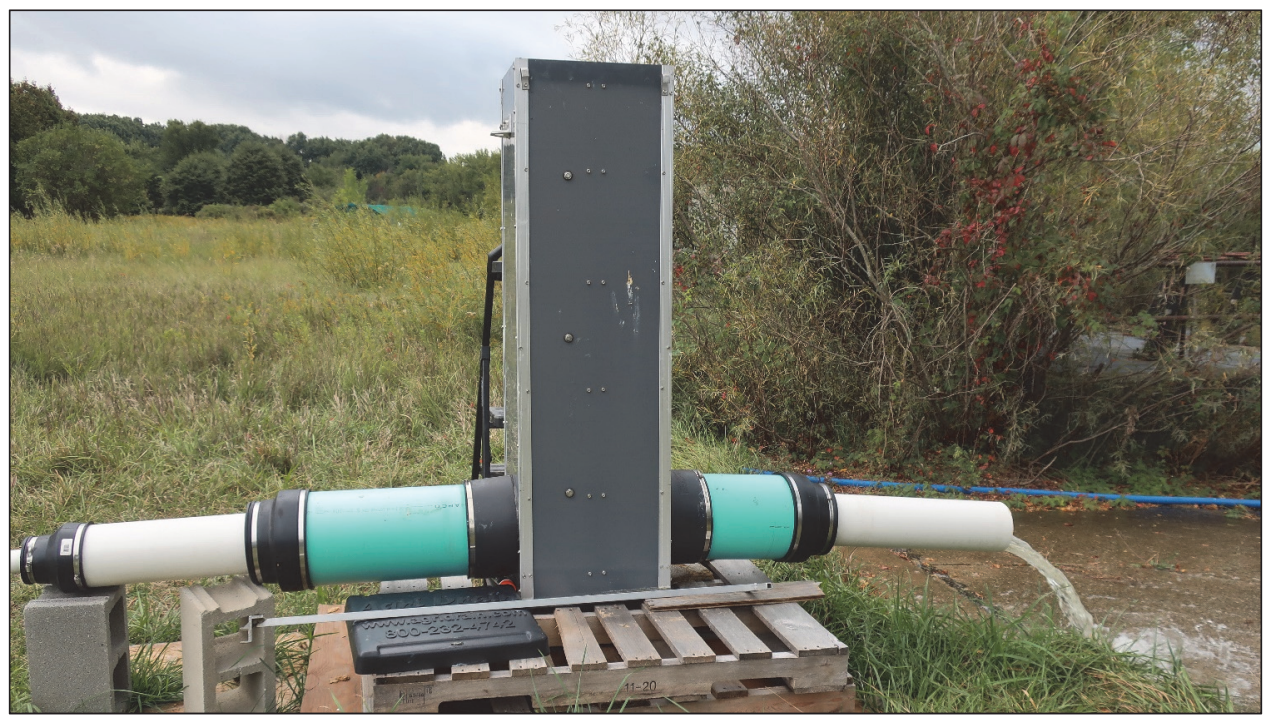

(b)

Figure 1. (a) Diagram of the experimental setup showing water flow through a V-notch weir. (b) Sideview photo of the control structure with flowing water (This image was taken during a test run of the experiment. We made sure the drain pipes were leveled before and during the experiment) 

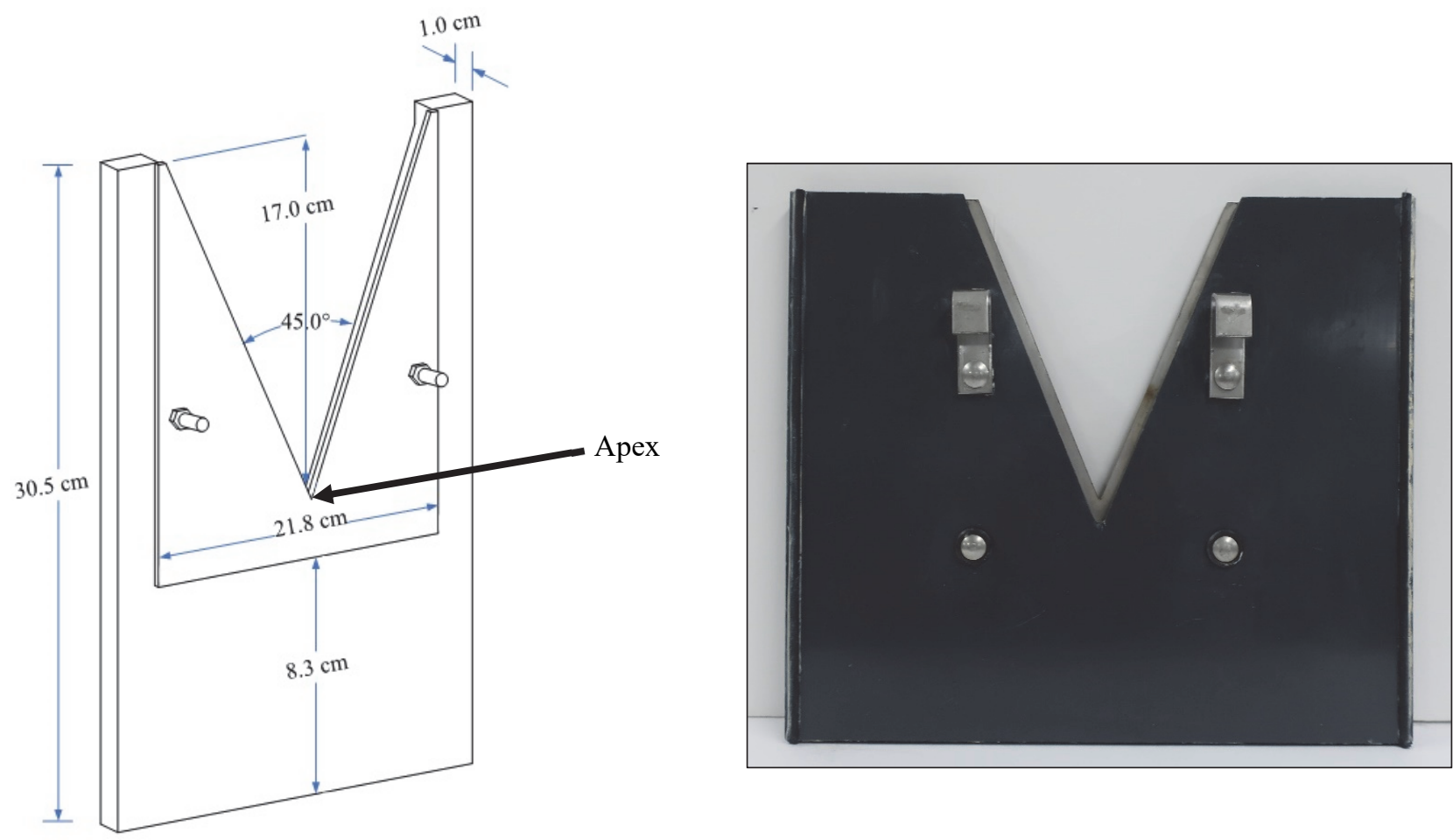

Figure 2. (Left) Schematic diagram of a metal-edge sharp-crest $45^{\circ} \mathrm{V}$-notch weir. The apex is the point at which both inclined sides of the metal crest meet. The dimensions of the V-notch weir do not include the thickness of the rubber gaskets attached to the board. (Right) Photo of the metal-edge sharp-crest $45^{\circ} \mathrm{V}$-notch weir.

\section{Head Measurement Procedure}

\section{Phase 1. Water-level and Measurement of the Height of the Structure}

To determine the head of water inside the $\mathrm{V}$-notch weir, we put a PVC pipe along the wall of the control structure and made holes in it so that water can seep through that hole and maintain the same head as the control structure inside that pipe, but with less instability. Afterwards, we lowered a waterdepth sensor (model 101 P2, Solinst Canada Ltd.) inside the PVC pipe to measure the head for each flow reading obtained from the flow meter and the weighing method (fig. 3). This water-depth sensor provided the distance from the top of the control structure to the upstream water surface (distance "a"). We also measured the distance from the top to the bottom of the control structure (distance "b") with a tape measure.

\section{Phase 2. Measurement of the Height of the Apex of the $V$-notch and the Procedure for its Verification}

We measured the height of the apex of the V-notch using a top-down approach. In this approach, we measured the distance from the top of the control structure to the apex of the V-notch (distance "c" in fig. 3) with a meter-stick (fig. 4). Then, the distance from the top of the structure to the apex of the V-notch was measured by placing another ruler on the top and reading the value on the vertical meter stick (fig. 4b). The height of the $\mathrm{V}$-notch apex was calculated by estimating the distance "b-c", shown in figure 3.

\section{Phase 3. Equation for Head Calculation}

Based on the measured distances in phases 1 and 2 (fig. 3), head was calculated as:

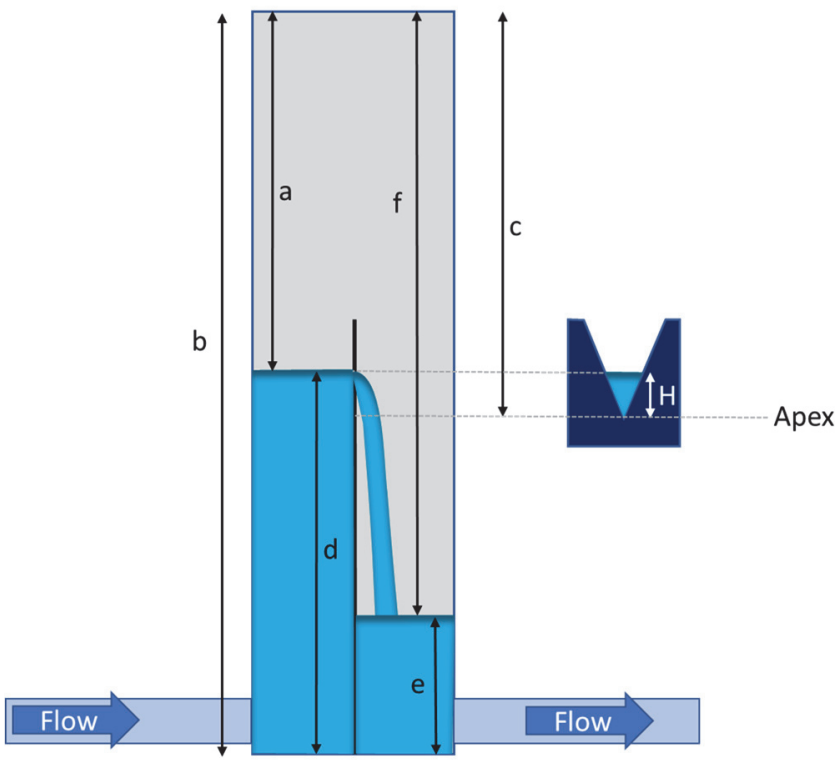

Figure 3. Diagram of the side view of a control structure and the distances needed to calculate the head $(\mathrm{H})$ flowing through a $\mathrm{V}$-notch weir using equation 5. A Solinst water-depth sensor was used to measure the distance "a" from the top of the structure to the upstream water surface and "f" from the top of the structure to the downstream water surface. A tape measure was used to measure the distance " $b$ " inside the structure, and a meter-stick was used to measure the distance "c" from the top of the structure to the apex of the V-notch weir. Distance "d" was calculated by subtracting "a" from " $b$ ". 

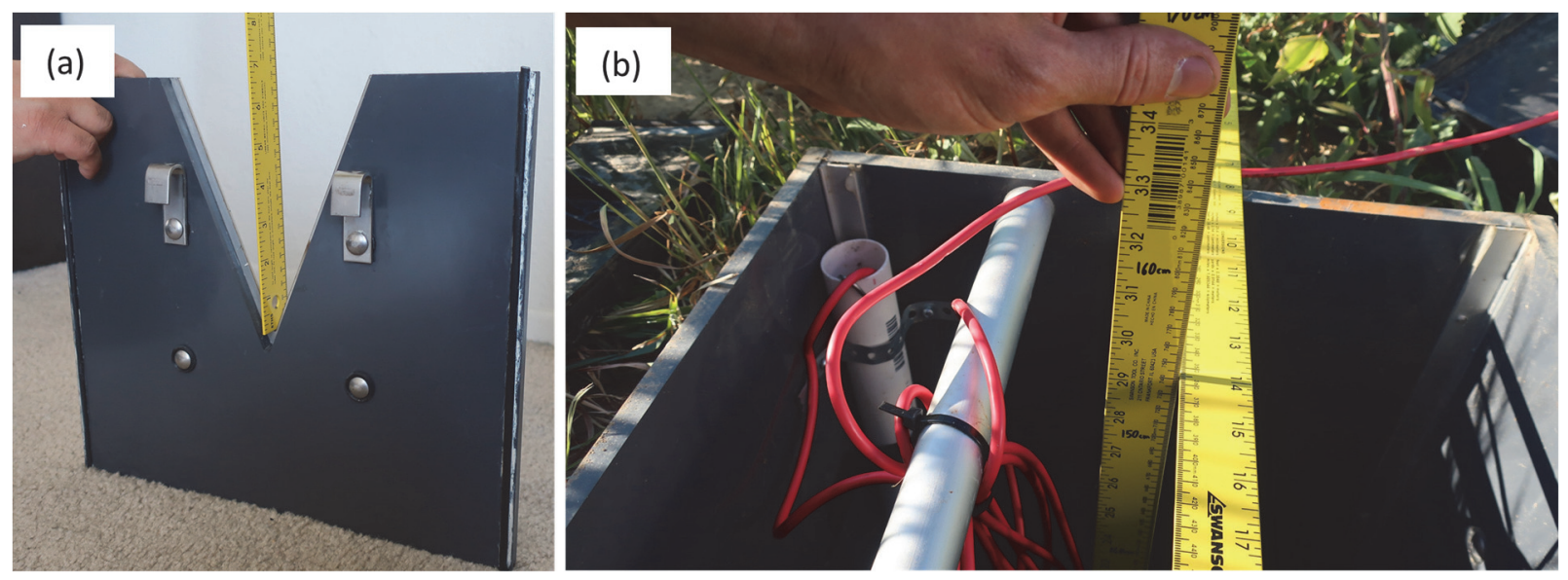

Figure 4. Measurement of the distance "c" from the top of the control structure to the apex of the V-notch weir. Multiple meter-sticks were glued and riveted together to make a long one. To measure the distance "c": (a) We lowered the meter-stick inside the apex of the $V$-notch weir, and (b) next, we measured the distance from the apex to the top of the structure by placing another ruler on the top and reading the value on the vertical meter stick.

$$
\mathrm{H}=(\mathrm{b}-\mathrm{a})-(\mathrm{b}-\mathrm{c})
$$

where

$\mathrm{a}=$ distance from the top of the control structure to the upstream water surface $(\mathrm{cm})$,

$\mathrm{b}=$ distance from the top of the control structure to the bottom (the height of the structure, $\mathrm{cm}$ ),

$\mathrm{c}=$ distance from the top of the control structure to the apex of the $\mathrm{V}$-notch weir $(\mathrm{cm})$, and

$\mathrm{H}=$ head of water $(\mathrm{cm})$.

\section{Quality Control Measures}

We ensured high-quality data collection by taking cautionary steps throughout the experiment. These are listed below.

1. According to the manufacturer's user manual, we maintained the optimum pipe length for the turbine flow meter. Based on the turbine flow meter manual, the upstream and downstream pipe lengths of the flow meter should be at least ten (10) times and five (5) times the diameter of the turbine (i.e., $5 \mathrm{~cm}$ ), respectively. In our experiment, the upstream pipe length of the flow meter was $101.6 \mathrm{~cm}$ (20 times the turbine's diameter) and the downstream pipe length was $50.8 \mathrm{~cm}$ (10 times the turbine's diameter).

2. We checked the level of the whole setup before and during the experiment, including the control structure and the pipes, to ensure that the setup was horizontal.

3. We made sure that the turbine of the flow meter was not clogged with algae. We disconnected the flow meter from the pipes before, during, and after the experiment. Then, we visually checked for algae, and we did not find any algae in the turbine of the flow meter.

\section{DEVELOPING THE EMPIRICAL FLOW EQUATION WITH REGRESSION ANALYSIS}

We used a least squares regression to develop the empirical flow equation for this experiment. Measured flow rates were plotted against the corresponding head measurements, and the coefficient of determination ( $R$-squared) was used to evaluate the goodness of fit.

\section{RESULTS AND DISCUSSION V-NOTCH APEX HEIGHT MEASUREMENT USING TOP- DOWN APPROACH}

We measured the distances "b" and "c" (fig. 3) with the top-down approach. Distance " $b$ " was $149.8 \mathrm{~cm}$ and distance "c" was $118.1 \mathrm{~cm}$, so that the distance "b-c" was $31.7 \mathrm{~cm}$, which is the height of the $\mathrm{V}$-notch apex, that is, the distance from the structure bottom to the $\mathrm{V}$-notch apex, as measured with the top-down approach. The distance "b-c" was constant for all head measurements. It is important to mention that the distance " $b-c$ " represented the field condition where the V-notch board was placed on top of a 17.8-cm (7-in) bottom board, and the rubber gaskets attached to those boards were compressed.

\section{Calibrated V-Notch Weir Equation}

The least squares regression showed a strong relationship $(R$-square $=0.999)$ between head and flow rate (fig. 5). The empirical stage-discharge relationship equation is written as:

$$
\mathrm{Q}=0.749 \mathrm{H}^{2.25}
$$

where

$\mathrm{Q}=$ flow rate $(\mathrm{L} / \mathrm{min})$, and

$\mathrm{H}=$ head of water $(\mathrm{cm})$.

Christianson et al. (2019) tested their V-notch flow equation for two different control structure sizes (15 and $25 \mathrm{~cm})$. The authors concluded that the $\mathrm{V}$-notch flow equation could be used for other control structures, regardless of their size. They also tested their equation by placing the V-notch weir at three different heights inside each of the different sized structures. They found no statistically significant difference in the flow equations among three different $\mathrm{V}$-notch weir placements. Consequently, we expect that our empirical equation will be valid for structures of different sizes when the same AgriDrain metal-edge sharp-crest $45^{\circ} \mathrm{V}$-notch weir is used. 


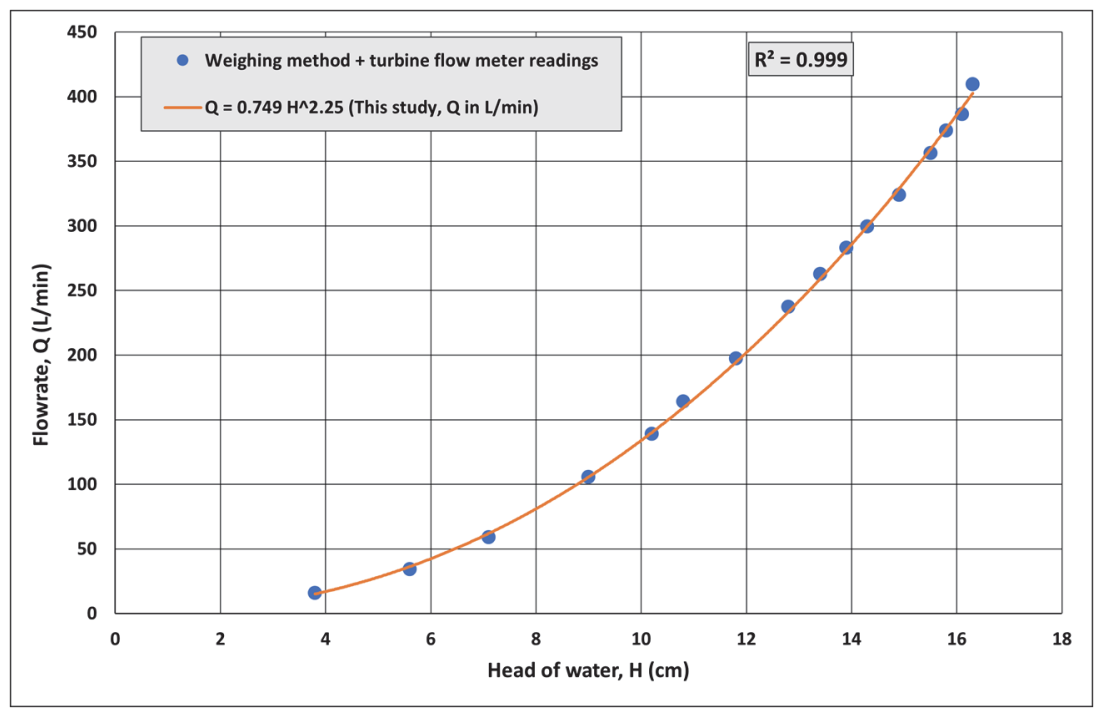

Figure 5. Calibration equation for a metal-edge sharp-crest V-notch weir. We developed this equation for a maximum flow rate of $409.42 \mathrm{~L} / \mathrm{min}$ with a head of $16.3 \mathrm{~cm}$. We used the weighing method for the low flow rates $(16-59 \mathrm{~L} / \mathrm{min})$ and the flow meter for the higher flow rates $(105-409 \mathrm{~L} / \mathrm{min})$. This equation is valid for an $\mathrm{H}$ less than the height of the $\mathrm{V}$-notch (i.e., flow through the $\mathrm{V}$-notch). In our experiment, the height of the V-notch was $17.0 \mathrm{~cm}$.

\section{COMPARison With Previously Reported V-NOTCH WEIR EQUATIONS}

We compared the V-notch equation of this study to that of previous studies (fig. 6). The USGS (1982) equation (eq. 3) underestimated the flow rates for all the head measurements. This may be explained by the differences in the scope for application of these two equations. The equation developed in this study can estimate flow rates for $45^{\circ} \mathrm{V}$ notch weirs inside a $25-\mathrm{cm}$ AgriDrain control structure, whereas the USGS equation is used in different applications in an open-channel flow.

We developed our equation for a maximum flow rate of $409.42 \mathrm{~L} / \mathrm{min}$ with a head of $16.3 \mathrm{~cm}$. Our equation is valid for an $\mathrm{H}$ less than the height of the $\mathrm{V}$-notch (i.e., flow through the $\mathrm{V}$-notch). In our experiment, the height of the $\mathrm{V}$ notch was $17.0 \mathrm{~cm}$. The flow rates obtained from the equation developed in this study (eq. 6) are consistently higher than the equation developed by Christianson et al. (2019) (fig. 6). Christianson et al. (2019) used one method (weighing) of flow rate reading to develop their equation, but they did not calibrate and verify their weighing scale (i.e., load cell) as reported in Maxwell et al. (2021). Figure 6 shows that the equation from Christianson et al. (2019) underestimates the higher flow rates compared to the equation obtained in our study. This could be because their weighing scale was not calibrated and verified.

To assure the reliability of our equation (eq. 6), we obtained stage-discharge relationship data from a separate experiment conducted in Farrall Hall at Michigan State University. In that experiment, we used two turbine flow meters (one for low flow and one for high flow), different from the one used to develop equation 6. Comparison between that experiment (two flow meters) and the one conducted

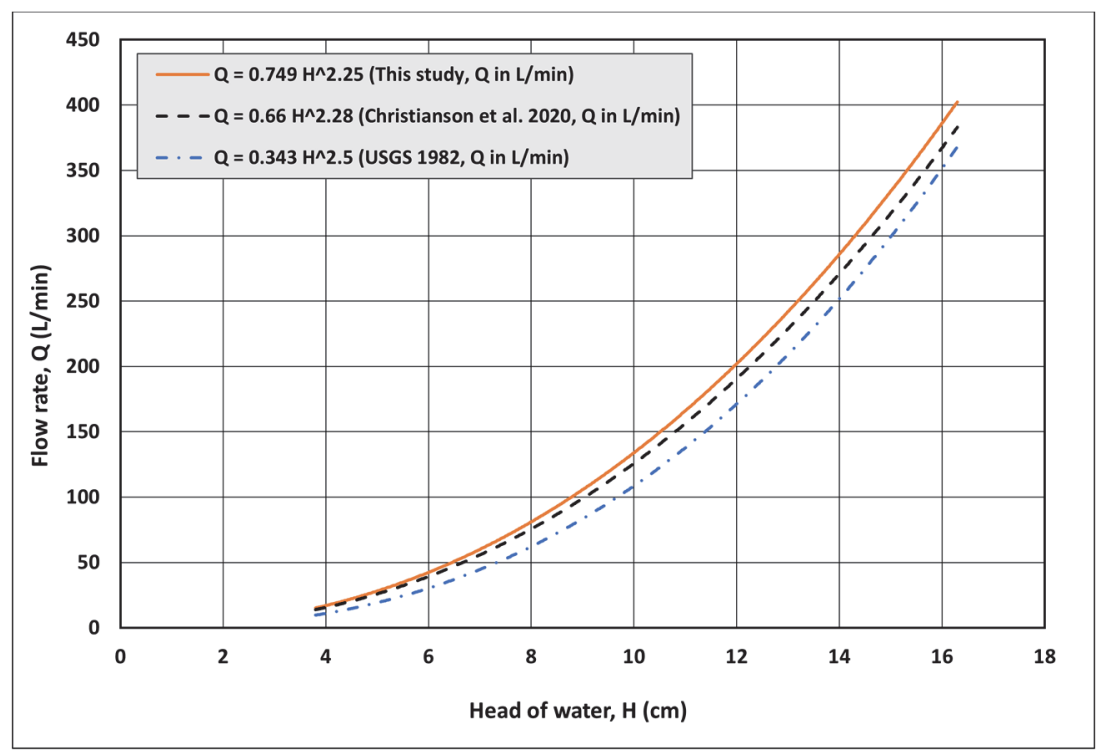

Figure 6. Comparison of the V-notch equation developed in this study to those in previous studies. 
herein shows that stage-discharge data closely agreed with each other (supplementary information: fig. S2, https://figshare.com/s/074abddcaa5da99095ff). Therefore, the two-turbine experiment verifies the stage-discharge equation 6 . For more information, refer to the supplementary information.

\section{Standard Procedure for ACCurately Measuring FLOW RATE}

Based on our combined results and experiences, we provided a standard procedure for accurately estimating drainage discharge. These steps can be used for rectangular or cylindrical structures.

\section{Step 1: Measure the Height of the Control Structure (distance " $b$ " in fig. 3)}

Measure the distance from the top to the bottom of the control structure with a tape measure, making sure that the tape measure is in contact with the structure wall so that it doesn't bend.

\section{Step 2: Measure the Depth of the V-notch Apex (distance " $c$ " in fig. 3)}

Measure the distance from the top of the control structure to the V-notch apex, distance "c", by first placing a long, thin measuring stick inside the apex. Then, carefully measure distance "c" by placing another ruler on the top of the control structure and reading the value on the vertical meter stick (fig. 4).

\section{Step 3: Measure the Upstream Water-level from Top or Bottom of the Structure (distance "a" or "d" in fig. 3, respectively)}

There are at least two methods for measuring the water level from the bottom of the control structure (distance "d" in fig. 3): a pressure transducer or a water-finding paste.

The pressure transducer method is useful for measuring the water level when continuous flow rates will be measured. The pressure transducer is placed inside a PVC pipe and lowered to the bottom of the upstream chamber of the structure. The PVC pipe reduces the effects of flow turbulence on the pressure transducer. To ensure accurate water-level measurements, the pressure transducer reading is verified with manual water-level measurements regularly (e.g., with water-finding paste) and sediments are removed from the pressure transducer as they accumulate.

The second method is useful for measuring water level when the instantaneous flow rate will be measured. This method requires a meter stick and water-finding paste. The water-finding paste is applied on a meter stick and then slowly lowered to the bottom of the control structure. The meter stick is lowered along the wall of the upstream chamber of the control structure to ensure that it does not bend. The paste will turn red upon contact with water (fig. 7).

Various water-depth sensors are available to measure the water depth from the top of the structure (distance "a" in fig. 3) as performed in this study. Some of them need to contact water to measure the depth (fig. 8a). Others are contactless, for example, an ultrasonic level sensor. Both methods are used when measuring instantaneous flow rate. The sensors that need to contact water for depth measurements (e.g., the one from Solinst) usually consist of a probe connected to

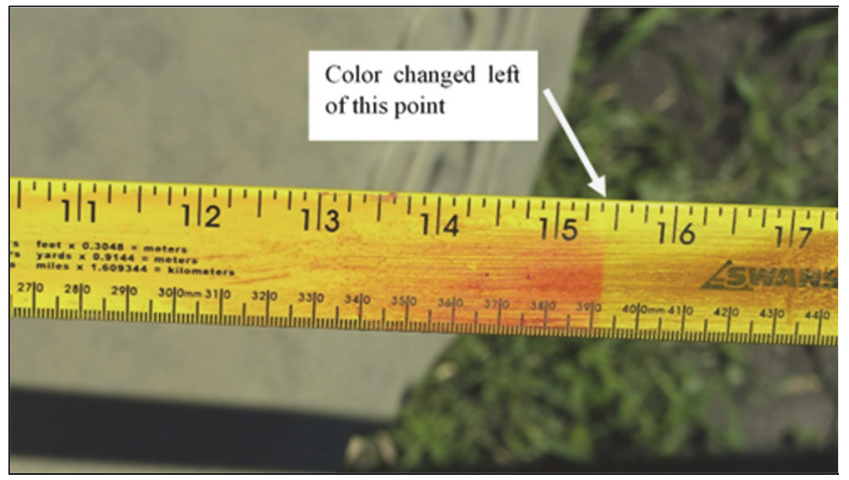

Figure 7. Measurement of water level with water-finding paste. A small amount of paste is applied to a meter stick, which is inserted into water. The dry paste is white but turns red upon contact with water.

a flat tape measure. When using this type of sensor, the probe is lowered into the upstream chamber of the control structure near the wall (fig. 8b). Once the probe meets the water surface, the unit will emit both sound and light signals. At that time, the value on the flat tape, read by looking at the marked numbers vertically, is an estimate of the water depth inside the control structure, distance "a" in figure 3.

Another sensor for measuring water depth from the top of the structure is an ultrasonic sensor, which is currently being investigated by researchers to determine if it works with the AgriDrain control structures.

\section{Step 4: Measure the Downstream Water-level from Structure Top or Bottom (distance "f" or " $e$ " in fig. 3)}

It is important to measure the water level in the downstream chamber of the control structure to ensure flow impedance (i.e., submerged flow) does not occur. This means that the water level in the downstream chamber must not rise above the Vnotch apex. The downstream water depth can be measured from the structure top (distance "b-f") using a water-depth meter. It is also possible to measure the downstream water level from the bottom (distance "e") with a pressure transducer or water-finding paste. The details about these measurement procedures are explained in step 3. Our calibrated equation will not be valid under submerged flow conditions.

\section{Step 5: Calculate Head Inside the V-notch Weir}

To calculate head inside the structure when the height of the water level in the upstream chamber (distance " $\mathrm{d}$ " in fig. 3) can be identified from a pressure transducer or from the water-finding-paste method, use the following equation:

$$
\mathrm{H}=\mathrm{d}-(\mathrm{b}-\mathrm{c})
$$

To calculate head when the depth of water in the upstream chamber (distance "a" in fig. 3) can be determined from a water-depth meter, use equation 5.

\section{Step 6: Calculate Flow Rate}

Use equation 6 to calculate flow rate based on a measured head when the following two conditions are met: (1) water must be flowing through the $\mathrm{V}$-notch weir and not flowing over the weir (that is, $H<17.0 \mathrm{~cm}$ for this study) and (2) the height of the water level in the downstream chamber (distance "e" in fig. 3) must not exceed the V-notch apex (distance "b-c" in fig. 3), so that submerged flow is avoided. 

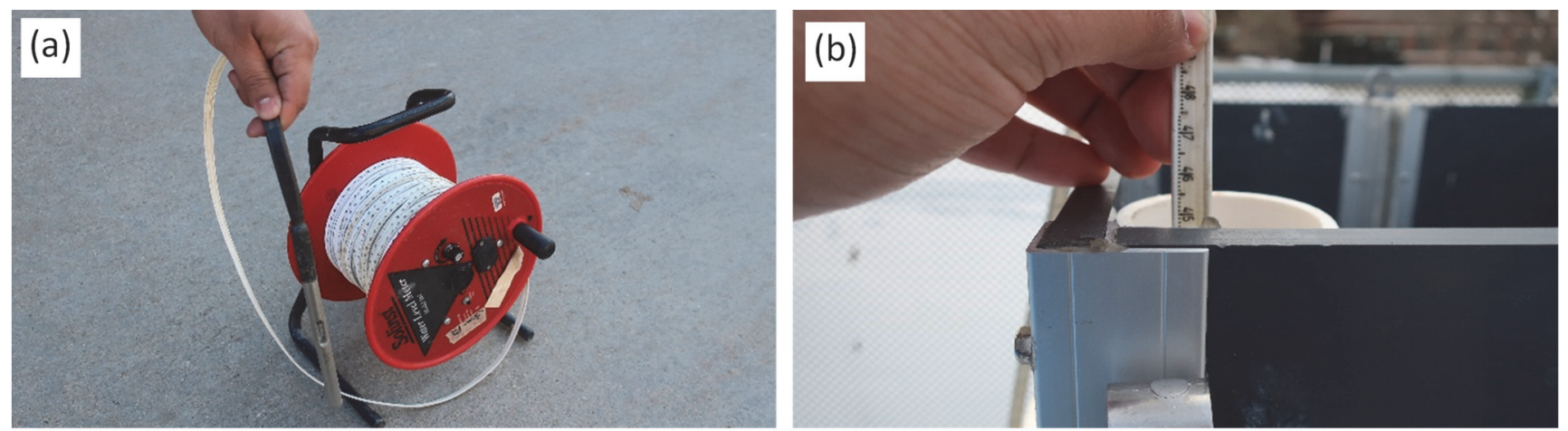

Figure 8. Measurement of water level using a water-depth sensor: (a) Solinst water-depth sensor; the sensor is located at the middle of the probe. Once the sensor comes in contact with water, sound and light signals will indicate when to take the reading. (b) The sensor probe is lowered inside the control structure through a PVC pipe to reduce the effect of flow turbulence. Once in place, the length of the flat tape along the wall of the control structure indicates the water depth.

\section{THINGS TO AVOID WHEN Following THE STANDARD PROCEDURE \\ Avoid Adding Nominal Board Sizes to Measure Height of V-notch Apex}

A common method of estimating the height of the $\mathrm{V}$ notch apex (distance "b-c" in fig. 3) is to add the nominal sizes of boards, which could introduce errors. When adding nominal board sizes, the thickness of the rubber gaskets will be neglected. To demonstrate this point, we estimated the height of the V-notch apex by adding two nominal 5-in. boards, one nominal 7-in board, one nominal 7-in bottomboard, and a standard metal-edge sharp-crest $45^{\circ} \mathrm{V}$-notch board. Based on adding nominal board sizes, the height of the V-notch apex was $74.5 \mathrm{~cm}$. Based on the top-down approach, we determined the height of the V-notch apex to be $74.9 \mathrm{~cm}$; there is a difference of $0.4 \mathrm{~cm}$ between the two measurements, perhaps due to the thickness of the rubber gaskets, or variations between the nominal and actual board sizes. If not considered, these factors could result in an error in the measurement of the V-notch apex height. At the end of 2013, AgriDrain replaced the traditional boards with foam gaskets (or foam O'rings) with the injection-molded boards with rubber gaskets. The compressed thickness of the new rubber gaskets may not be the same as the foam ones. This error would be even greater if more boards were used inside the control structure. Therefore, nominal board sizes should not be used to estimate the height of the V-notch apex (distance "b-c" in fig. 3), unless the height of each board is carefully measured and the thickness of compressed rubber gaskets is included.

\section{Avoid Using a V-notch Weir Board without a Bottom Board}

During heavy rainfall, the water level in a ditch may rise and create outlet submergence (fig. 9). In this situation, the water level in the downstream chamber of the structure can rise above the $\mathrm{V}$-notch apex, thus preventing the use of equation 6 because water is no longer freely flowing through the V-notch. However, if a bottom board is used, the equation 6 can be used to calculate flow as long as the water level in the downstream chamber remains below the $\mathrm{V}$-notch apex. If the downstream water level rises higher than the apex, the Vnotch weir will be submerged, and equation 6 will no longer be valid. Overall, the benefit of using a bottom board is that it gives that extra height to the apex of the V-notch weir, so there is a greater chance of achieving freely flowing water through the V-notch.

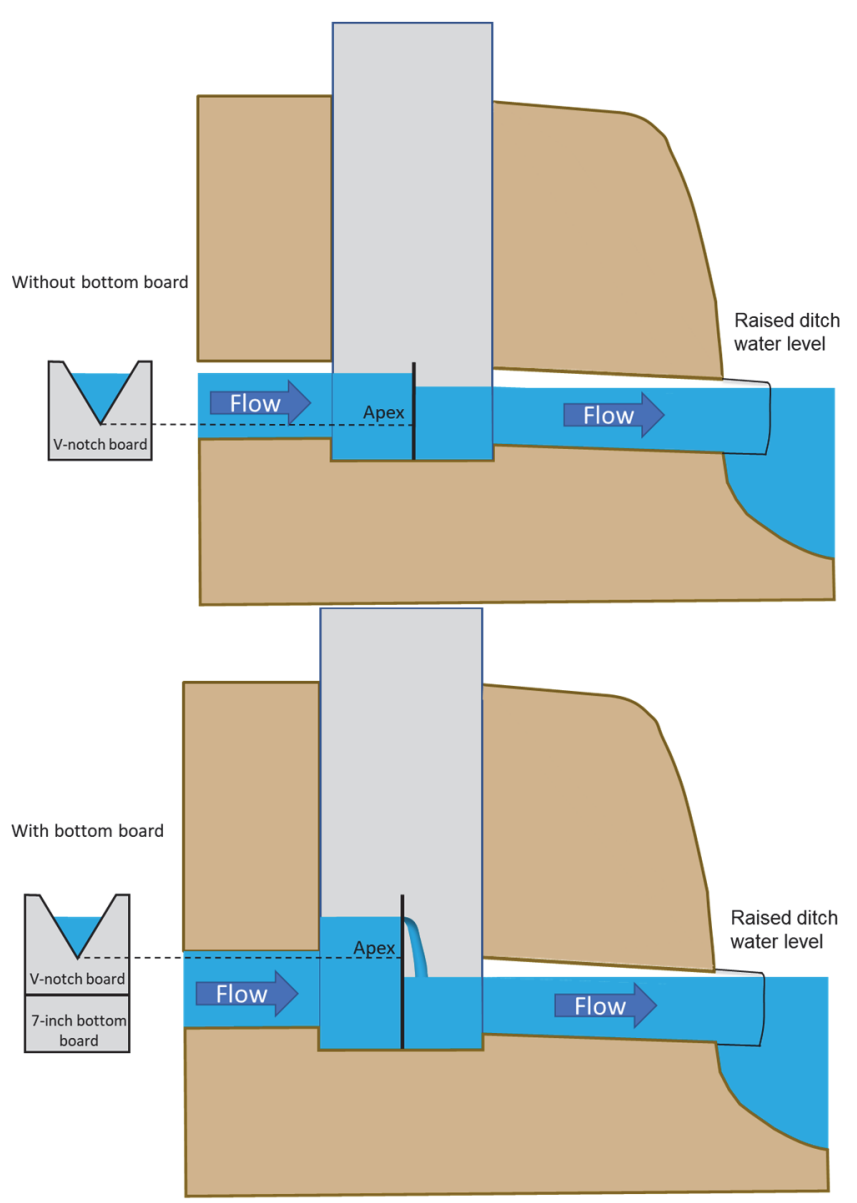

Figure 9. A diagram (not drawn to scale) to represent the water flow inside a $25-\mathrm{cm}$ control structure in agricultural fields. (Top diagram) If there is heavy rainfall, the water level in the ditch will rise and the water level in the downstream chamber of the control structure will rise above the apex of the V-notch, causing submerged flow. (Bottom diagram) Adding a 17.8-cm (7-in.) bottom board below the $V$-notch weir would give extra height to the apex of the $V$-notch weir, so there would be a greater chance of achieving freely flowing water through the V-notch. 


\section{CONCLUSIONS}

We measured head and flow rate for a metal-edge sharpcrest $45^{\circ}$ V-notch weir inside a $25-\mathrm{cm}$ AgriDrain control structure. Based on those measurements, we developed an empirical stage-discharge equation while following qualitycontrol procedures. In our calibration procedure, we used a weighing method for the lower flow rates and a turbine flow meter for the higher flow rates. The empirical metal-edge sharp-crest $45^{\circ} \mathrm{V}$-notch weir equation can be used for any AgriDrain control structure, as long as the water is flowing through the $\mathrm{V}$-notch weir and there is no flow submergence. If using a cylindrical control structure, we recommend developing a stage-discharge equation before drainage monitoring. Based on field experience, we provide a standard procedure to accurately estimate drainage discharge. In conclusion, the V-notch weir equation developed in this study can provide reliable flow estimates that can be used to estimate nutrient load reductions in subsurface drainage studies.

\section{ACKNOWLEDGEMENTS}

This research was funded by the Michigan Department of Agricultural and Rural Development (grant\# 791N7700580). We express gratitude to Babak Dialameh and Yousef Abdalaal for aiding with data collection and illustrations for this study. We thank AgriDrain for donating a control structure for this experiment.

\section{REFERENCES}

Bijankhan, M., \& Ferro, V. (2017). Dimensional analysis and stagedischarge relationship for weirs: A review. J. Agric. Eng., 48(1), 1-11. https://doi.org/10.4081/jae.2017.575

Chanson, H., \& Wang, H. (2013). Unsteady discharge calibration of a large v-notch weir. Flow Meas. Instrum., 29, 19-24. https://doi.org/10.1016/j.flowmeasinst.2012.10.010

Christianson, L. E., Christianson, R. D., Lipka, A. E., Bailey, S., Chandrasoma, J., McCoy, C.,... Cooke, R. A. (2019). Calibration of stainless steel-edged v-notch weir stop logs for water level control structures. Appl. Eng. Agric., 35(5), 745-749. https://doi.org/10.13031/aea.13350

Christianson, L., Bhandari, A., Helmers, M., Kult, K., Sutphin, T., \& Wolf, R. (2012). Performance evaluation of four field-scale agricultural drainage denitrification bioreactors in Iowa. Trans. $A S A B E$, 55(6), 2163-2174. https://doi.org/10.13031/2013.42508

Chun, J. A., \& Cooke, R. A. (2008). Calibrating agridrain water level control structures using generalized weir and orifice equations. Appl. Eng. Agric., 24(5), 595-602. https://doi.org/10.13031/2013.25274

Fausey, N. R., Brown, L. C., Belcher, H. W., \& Kanwar, R. S. (1995). Drainage and water quality in Great Lakes and Cornbelt States. J. Irrig. Drain. Eng., 121(4), 283-288. https://doi.org/10.1061/(ASCE)0733-9437(1995)121:4(283)

Ghane, E., Fausey, N. R., Shedekar, V. S., Piepho, H. P., Shang, Y., \& Brown, L. C. (2012). Crop yield evaluation under controlled drainage in Ohio, United States. JSWC, 67(6), 465-473. https://doi.org/10.2489/jswc.67.6.465
Ghane, E., Ranaivoson, A. Z., Feyereisen, G. W., Rosen, C. J., \& Moncrief, J. F. (2016). Comparison of contaminant transport in agricultural drainage water and urban stormwater runoff. $P L o S$ One, 11(12), e0167834.

https://doi.org/10.1371/journal.pone.0167834

Haan, C. T., Barfield, B. J., \& Hayes, J. C. (1994). Design hydrology and sedimentology for small catchments. Cambridge, MA: Elsevier.

Huffman, R. L., Fangmeier, D. D., Elliot, W. J., Workman, S. R., Schwab, G. O. (2013). Soil and water conservation engineering. American Society of Agricultural and Biological Engineers St. Joseph.

Jaynes, D. B., \& Isenhart, T. M. (2014). Reconnecting tile drainage to riparian buffer hydrology for enhanced nitrate removal. JEQ, 43(2), 631-638. https://doi.org/10.2134/jeq2013.08.0331

Kanwar, R. S., Bjorneberg, D., \& Baker, D. (1999). An automated system for monitoring the quality and quantity of subsurface drain flow. J. Agric. Eng. Res., 73(2), 123-129. https://doi.org/10.1006/jaer.1998.0398

King, K. W., Fausey, N. R., \& Williams, M. R. (2014). Effect of subsurface drainage on streamflow in an agricultural headwater watershed. J. Hydrol., 519, 438-445. https://doi.org/10.1016/j.jhydrol.2014.07.035

King, K. W., Williams, M. R., \& Fausey, N. R. (2015). Contributions of systematic tile drainage to watershed-scale phosphorus transport. JEQ, 44(2), 486-494. https://doi.org/10.2134/jeq2014.04.0149

Konyha, K. D., Skaggs, R. W., \& Gilliam, J. W. (1992). Effects of drainage and water-management practices on hydrology. $J$. Irrig. Drain. Eng., 118(5), 807-819. https://doi.org/10.1061/(ASCE)0733-9437(1992)118:5(807)

Maxwell, B. M., Cooke, R. A., Christianson, R. D., Christianson, L. E. (2021). Stage-discharge relationships of Drawdown plates for denitrifying woodchip bioreactors. Appl. Eng. Agric. (in press). https://doi.org/10.13031/aea.14633

Mourtzinis, S., Andrade, J. F., Grassini, P., Edreira, J. I., Kandel, H., Naeve, S.,... Conley, S. P. (2021). Assessing benefits of artificial drainage on soybean yield in the North Central US region. Agric. Water Manag., 243, 106425. https://doi.org/10.1016/j.agwat.2020.106425

Pease, L. A., King, K. W., Williams, M. R., LaBarge, G. A., Duncan, E. W., \& Fausey, N. R. (2018). Phosphorus export from artificially drained fields across the Eastern Corn Belt. J. Great Lakes Res., 44(1), 43-53. https://doi.org/10.1016/j.jglr.2017.11.009

Schilling, K. E., \& Helmers, M. (2008). Effects of subsurface drainage tiles on streamflow in Iowa agricultural watersheds: Exploratory hydrograph analysis. Hydrol. Process., 22(23), 4497-4506. https://doi.org/10.1002/hyp.7052

Troskolanski, A. T. (1960). Hydrometry: Theory and practice of hydraulic measurements. Pergamon Press.

USGS. (1982). Measurement and computation of streamflow. Computation of discharge. USGS Water Supply Paper 2175 2, 32. USGS.

Walkowiak, D. K. (2006). ISCO open channel flow measurement handbook.

Williams, M. R., King, K. W., \& Fausey, N. R. (2015). Drainage water management effects on tile discharge and water quality. Agric. Water Manag., 148, 43-51. https://doi.org/10.1016/j.agwat.2014.09.017

World Meteorological Organization (1971). Use of weirs and flumes in stream gauging, WMO Technical Note No. 117. World Meteorological Organization. 